\title{
Humanitarian crisis and sustainable development: perspectives and preferences of internally displaced persons in the northeastern Nigeria
}

\author{
Muazu Shehu* (i) and Adamu Abba
}

\begin{abstract}
This study seeks to contribute to the knowledge of linkages between humanitarian actions in conflict situations and sustainable development. We analysed data generated from qualitative interviews and focus group discussions with encamped and self-settled internally displaced victims (IDPs) of the Boko Haram insurgency in the northeastern Nigeria. Our analysis searched for themes that summarise their preferences and desires of durable solutions. Overall, the majority of the IDPs were more inclined to local integration or resettlement than return. More than males, female IDPs were likely to cite personal experience of violence as a reason for rejecting voluntary repatriation. Feelings of vulnerability, experience of violence and hope of economic and social empowerment were major reasons given in support of local integration or resettlement. Self-settled IDPs are more disposed to returning to their places of origin than encamped IDPs. The need to rebuild livelihoods and restore social and community networks were the major factors participants associated with the choice of return. Beliefs in divine destiny, lack of trust and confidence in the government were dominant views expressed by participants who were indifferent about durable solutions. There is a sense that cultural androcentric norms which give men the power to make decisions for the family shape decision-making even in emergency situations. We conclude that, regardless of their preferences about durable solutions, IDPs have long-term needs that can only be provided if humanitarian actions are integrated into the overall development agenda and programmes of governments.
\end{abstract}

Keywords: Humanitarian crises, Internal displacement, Durable solutions, Sustainable development

\section{Introduction}

Humanitarian emergencies remain one of the biggest development challenges of the twentyfirst century. Despite the growing efforts to address the challenges of poverty and inequality as they affect the most vulnerable members of developing countries, sustainable development agendas and programmes, until recently, did not seem to give much attention to all categories of vulnerable individuals and groups. The initial focus of sustainable development efforts was primarily on long-term programmes that aim to tackle poverty, social

\footnotetext{
* Correspondence: muazusu@gmail.com; Muazu.Shehu@rcc.Imu.de
} Department of Sociology, Gombe State University, Gombe, Nigeria inequalities, environmental decline, etcetera, while also addressing structural issues that undermine growth, prosperity and sustainability. On the other hand, humanitarian interventions in conflict situations and areas affected by environmental catastrophes tend to prioritise saving lives, alleviating stress and providing relief materials (Schafer 2002). Even when humanitarian actions seek to achieve long-term solutions to violence, persecution and displacement, such efforts often ignore how those solutions affect or are affected by the overall development programmes of governments.

Recently, the scholarship on sustainability and development (Tamminga 2011; CGDEV (Center for Global 
Development) 2017; Blind 2019) as well as international development initiatives such as the Sustainable Development Goals (SDGs) 16 has begun to recognise the importance of linking development interventions with humanitarian crises in volatile regions and areas affected by natural disasters. The linkages between sustainable development and humanitarian emergencies caused by natural disasters have been explored by a number of studies (Schipper and Pelling 2006; Eriksen and O'Brien 2007; Strömberg 2007). A common theme in these studies is that vulnerability, poverty and suffering that follow natural disasters have significant implications for development policy. Disasters increase poverty and reverse development when people lose lives and livelihoods. Poverty deprives people of food, health, education and other resources. Lack of resource further contributes to vulnerability and increases the risk of suffering (injury, death and loss of livelihoods) in the face of health hazards, natural disasters and violence. Policy response to emergencies need to involve long-term development interventions aimed at enhancing economic and social development, reducing poverty, rebuilding sustainable livelihoods and strengthening the resilience of populations to future shocks (Eriksen and O'Brien 2007). Thus, addressing the underlying causes of vulnerability to the impacts of emergencies is crucial to sustainable development. Scholarly attention is also shifting towards humanitarian emergencies caused by conflicts and violence. As studies such as Blind (2019) suggest, since humanitarian crises that result from civil wars and other violent conflicts are inherently developmental challenges, they cannot be solved using quick interventions and short-term measures. Their solutions need to include long-term development programmes that can lead to stability and development (Tamminga 2011).

On the policy realm, the United Nations Sustainable Development Goals (SDGs) 16 seeks to put humanitarian interventions at the heart of the development agenda of the international community. The goals stress the need to gear efforts toward building strong institutions that will bring about peace and justice in places bedevilled by conflicts, violence and other emergencies. In the international responses to conflict-induced humanitarian crises, there are now renewed efforts to move beyond providing immediate relief materials (such as food, clothing, shelter, essential medications) to restoring destroyed livelihoods, rehabilitating individuals and communities, building resilience and reducing risks, and preventing further spread of conflict. Experts believe that these efforts can only achieve the desired results if adequate attention is paid to gaining a better understanding of the peculiar livelihood needs and conditions of the people and communities affected by violent conflicts, how meeting those needs fits into or reflects the overall long-term interest of sustainability and how humanitarian and development interventions can be conceptualised to integrate those livelihood needs and conditions.

This paper seeks to contribute to our understanding of the linkages between humanitarian emergencies and sustainable development. The aim is to get a better understanding of preferences and perceptions of internally displaced persons (IDPs) who fled the Boko Haram conflict in the northeastern Nigeria on traditional 'durable solutions' to displacement with a view to ascertain how their preferences reflect the overall goals of development and sustainability. As defined in the Inter-Agency Standing Committee's (IASC) framework on durable solutions to displacement (Inter-Agency Standing Committee 2010:A1), a durable solution entails creating a situation where IDPs 'no longer have any specific assistance and protection needs that are linked to their displacement and can enjoy their human rights without discrimination on account of their displacement'. This can be achieved through 'sustainable reintegration at the place of origin (return), sustainable local integration in areas where IDPs take refuge and sustainable integration in another part of the country (resettlement)'.

As a durable solution, local integration refers to the situation where IDPs voluntarily acquire the legal right to naturalise in their place of refuge, the economic right to establish 'sustainable livelihoods and a standard of living comparable to the host community', and the right to social and cultural adaptation and acceptance that enables them to 'contribute to the social life of the host community and live without fear of discrimination' (Fielden 2008:1). Resettlement implies the movement of displaced persons to a destination within the country other than their places of origin and refuge where they would have permanent residency. Like local integration, resettlement involves displaced persons acquiring all the legal, economic and social cultural rights comparable to members of the host community.

The Boko Haram insurgency that has continued to ravage the region of the Northeast Nigeria since 2009 has caused enormous damage to the economy, society and environment in the region. The conflict has led to the collapse of rural livelihood in much of Borno State, as well as in some parts of Adamawa and Yobe State. This conflict, according to the Office for the Coordination of Humanitarian Affairs (OCHA), has resulted in one of the most severe humanitarian crises in the world, with about 1.7 million people internally displaced; over 3 million people facing 'critical and crisis' levels of food and nutrition insecurity, and nearly 600,000 people in urgent need of protection (OCHA 2018). Overall, the United Nations Development Programme (UNDP) has estimated that the number of people in need of lifesaving humanitarian assistance as a result of the conflict 
has reach more than 10 million in 2018 (UNDP 2018). The humanitarian crisis is also responsible for widespread cases of gender-based violence, child abuse and trafficking, and severe public health challenges. According to the Federal Government of Nigeria, the war has also led to the destruction of over 1500 schools and the death of about 2295 and displacement of 19,000 teachers (Punch News 2018).

The region makes an interesting case for examining the links between humanitarian emergencies, development and sustainability. Even before the 10-year-old brutal insurgency by Boko Haram, the region was already affected by severe development challenges such as extreme poverty and profound environmental change (UNFCCC 2007; BBC World Trust 2010; UNDP 2018). For instance, the Nigerian Living Standard Survey (National Bureau of Statistics 2019) indicated that while $41.1 \%$ of the total population of Nigerian were classified as poor, about $72 \%$ of the people in the North Eastern Subregion were classified as poor. Similarly, a report by the Federal Ministry of Environment referred to the Northeast and Northwest regions as the most vulnerable of the six geopolitical zones to negative effects of climate change (Federal Ministry of Environment 2014). Despite these challenges, there are rarely any empirical studies that explore the links between the humanitarian crisis and responses and wider developmental issues affecting the region. Much of the current research on the crisis focuses on assessing the efficiency of humanitarian interventions or the plight and experiences of the victims. Such studies treat humanitarian emergencies as separate from deeply rooted challenges of development and sustainability. As Long (2014) observed, the thinking that informs both research and policy on forced migration which sees displacement as merely a humanitarian challenge instead of development challenge needs revisiting.

In the same vein, studies in development issues fail to recognise that the livelihood and protection needs of displaced persons and other people affected by brutal conflicts are different from those of other poor people in the society. This is because displaced victims of violence suffer from intrinsic risks such as loss of livelihoods, marginalisation, social disarticulation, emotional and psychosocial trauma, among other impoverishment risks. On the lack of appreciation of the peculiar development needs of people living in conflict situations, Long (2014) contends that one of the reasons why conventional solutions to displacement are failing is the failure to engage with broader development issues and how they affect displaced populations.

For sustainability in humanitarian action, there is an urgent need to gain a renewed understanding of the long-term development needs of IDPs by listening to their own voices. As Cohen (2008) observed, most decisions on internal displacement do not sufficiently reflect the needs of the displaced persons. Since sustainable development practitioners and humanitarian actors emphasise the agency of the poor and vulnerable groups, it is crucial to analyse the perspectives and preferences of these groups. By presenting a contextual analysis of the views of the displaced victims of the Boko Haram war, this study is likely to also help us gain a much better understanding of the challenges of existing policies on humanitarian intervention and development in the region.

\section{The institutional arrangement in response to the crisis}

To understand the humanitarian situation in the northeastern region of Nigeria, it is critical to give a brief background to the general institutional arrangement put in place in response to the crisis. Since the escalation of the Boko Haram conflict in 2014, humanitarian assistance was jointly provided by the government of Nigeria in collaboration with its local and international partners. The Federal Government of Nigeria through the National Emergency Management Agency (NEMA) is primarily responsible for the coordination of humanitarian interventions to people affected by the conflict. At regional (state) levels, there are agencies established to complement and support NEMA in providing assistance to the victims of the war. Because of the sheer scale of the humanitarian crisis in the region, national and regional humanitarian agencies require the support and expertise of local and international organisations.

According to officials interviewed, there are over 52 organisations providing humanitarian and developmental assistance to victims of the war. These agencies can be classified into three broad groups: The first group includes United Nations agencies such as the United Nations International Children's Emergency Fund (UNICEF), the World Health Organization (WHO), the United Nations Development Programme (UNDP), the International Organisation for Migration (IOM) and the United Nations Fund for Population Activities (UNFPA). The second group consists of International Nongovernmental Organisations (INGOs) such as the International Rescue Committee (IRC), the International Committee of the Red Cross (ICRC) and the Premiere Urgence Internationale (PUI). The last group includes Non-governmental Organisations (NGOs) such as the Nigeria Red Cross Society, Faith Based Organisations (FBOs), Community Based Organisations (CBOs) and Civil Society Organisations (CSOs).

Humanitarian actors in the Northeast Nigeria operate using the cluster approach. Also called 'sector system' approach, the cluster approach is developed to enhance accountability, predictability and better coordination of humanitarian response and recovery from emergencies. 
Under this approach, humanitarian response is coordinated through groups called clusters. A cluster is defined as a group of humanitarian organisations operating in one or more of the sectors of humanitarian action (e.g. protection, health, nutrition, education). Humanitarian actors in the Northeast region are grouped into clusters based on their mandate and responsibility. These mandates can be classified as either humanitarian or developmental. By their mandate, 'developmental' agencies such as UNDP and World Bank focus on recovery and transition stage of the emergency while 'humanitarian' agencies such as the IOM and United Nations High Commission for Refugees (UNHCR) handle humanitarian issues services such as psychosocial support, community mobilisation and protection (IOM 2015). There are, however, overlaps in the mandates and activities of the agencies operating in the region and some agencies fit into more than one cluster, thereby addressing both humanitarian and developmental issues. For instance, based on its mandate, the UNDP is tagged a developmental actor and the lead agency in transition and recovery working group. However, the agency is involved in the provision of immediate humanitarian assistance (UNDP 2020). Similarly, IOM is an agency that specialises on migration issues but belongs to education, health and other working groups that focus on recovery and transition (IOM 2015)

\section{Methodology and data}

To explore the perspectives and preferences of internally displaced persons in the Northeast Nigeria, we analysed data collected via 28 semi-structured interviews and 3 Focus Group Discussions (FGDs) with the internally displaced victims of the insurgency. The interviews were conducted in April and May 2018. The data was collected as part of a larger study on the crisis of large-scale displacement resulting from the Boko Haram war in the region. In the study, we explore institutional responses to displacement and exile, the impact of war and persecution on women and children, as well as the challenges to attaining durable solutions. Participants were recruited from three locations hosting thousands of internally displaced persons in Adamawa State of Nigeria. The locations are government-run Malkohi (housing 1329 IDPs) and Fufore (1726 IDPs) camps and Malkohi village host community (2030 IDPs).

Of the 28 interviews conducted, 16 were with male IDPs, while 12 were with female IDPs. All interviews and focus group discussions with encamped displaced persons were conducted with the permission of camp authorities. Access to self-settled IDPs was negotiated with the assistance of host community leaders and humanitarian volunteers. In line with established ethical requirements of social research, the study was sensitive to participants' needs while securing consent and during data collection. Adequate measures were taken to ensure the security, confidentiality and anonymity of all participants. The average interview lasted for about $33 \mathrm{~min}$, while focus groups lasted for about $65 \mathrm{~min}$ on the average. An interview guide was developed to help guide the conversation, prompting the researchers on the major themes or issues to prove while also letting the participants freely tell their stories without interruptions. All interviews were manually transcribed and coded using Nvivo 11 qualitative data analysis software. All data transcripts and audio records were stored securely and destroyed at the end of the study.

Like most qualitative studies, this study considers the research participants-IDPs-as social actors whose agency can facilitate or inhibit humanitarian relief policy and, as vulnerable members of the society, the wider development policy in the region. As social agents, IDPs' personal accounts of their experiences of the consequences of violence and displacement as well as their views on durable solutions in the aftermath of the conflict are crucial to understanding the intersection between humanitarian interventions and development in the region. Thus, a qualitative analysis procedure that sees IDPs as active agents-who have the capacity to influence the outcomes of humanitarian interventionswas used in this study. The coding process and analysis searched for themes that describe views of displaced persons on durable solutions, their long-term preferences and desires, as well as the reasons they gave to support their views.

A social scientific study of this nature, in such a volatile environment, is likely to face a number of ethical issues and practical challenges. We therefore wish to acknowledge that some ethical and practical challenges associated with field research in a volatile and insecure environment were encountered in the course of data collection. One of the challenges is that some IDPs initially expected that participation in the study would attract financial incentives and made efforts to influence the selection process. Another ethical challenge is the perception that their 'voices would be heard' and the study will lead to government taking measures to improve their living conditions. A major practical challenge encountered is we could not collect data in IDP camps and host communities in the city of Maidugiri, which hosts the largest concentration of IDPs in the region.

In tackling these challenges, we tried to be as transparent to our respondents as possible before and during interviews and FGDs. That is, we provided them with sufficient information about the purpose of the research, who we are, where we are working, who is sponsoring the study and how we are going to disseminate the findings. We secured informed consent of all participants 
who took part in the interviews and FGDS while promising to them anonymity and confidentiality in reporting the research findings. In addition, participants were given the liberty to choose to answer or not to answer any questions posed by the researchers.

\section{Results}

This section presents the analysis of data generated from qualitative interviews and focus groups. The data on preferences of durable solutions is presented under the three main headings, namely local integration and resettlement, return and indifference. Analysis of participants' preferences and views on acceptable lasting solutions to their displacement has found that local integration and resettlement are the most preferred solutions among all categories of IDPs, even though more self-settled IDPs than those in camps prefer voluntary repatriation. Local integration and resettlement are reported under the same heading, as most participants mixed the two options in their responses to questions regarding which solution is preferable to them. Also, the reasons given by this category of participants were found to be the same for local integration and resettlement. It is clear in the data that participants reduce solutions to displacement to two rather than three: return or no return. In this case, those who do not want to return are willing to accept either local integration or resettlement.

\section{Local integration and resettlement}

Concern over security and safety back home is the major reason IDPs gave for preferring to integrate in their place of displacement or resettle elsewhere in the country away from their homes. This concern is born out of previous experience of violence and trauma. Another important reason advanced by this category of participants is loss of livelihoods in their communities of origin, which makes them think that there are better opportunities for social and economic empowerment in local integration or resettlement than in voluntary repatriation.

\section{Personal experience of violence}

Some of the IDPs who indicated preference for local integration were emphatic during the interviews that they will never return to their homes:

"We'll never go back. Return is not an option at all to me. There is a challenge in return. I cannot go back ... I would prefer to remain here and integrate. But we cannot return to our homes. We have suffered enough. We can't." (001 encamped female IDP, Malkohi).

"You see the first option (return), I don't like it ... Even if I will be given a new house there and all that, I would prefer to stay here..." (002 Female encamped IDP, Malkohi)

When one of the participants quoted above was asked why she felt local integration or resettlement are better for her than return, she mentioned "fear" and "suffering" resulting from Boko Haram's violence and during their movement to safety as things she would not want to experience again:

"Because of the suffering we went through... Spending days and nights in the bush running for your life barefooted, in rain. You cooked food that you could not eat because of suffering and fear. That is it. So, I prefer to live the rest of my life somewhere far from our former home. If we can get the land to farm where one can get some food to feed one's family and a house to live, that is much better I believe." (001 Female encamped IDP, Malkohi)

Others were of the view that although they would like to return to their homes, local reintegration or resettlement is more tenable since security has remained a big challenge in their communities of origin. They maintained that they would not want a repeated experience of violence and trauma:

"Everybody wants to go back home since you were born there, and you grew up there. You would like to go back there if there is peace. But if there is no peace, then you must stay somewhere that the government gives to you. So, wherever you find yourself, to stay, where there is peace would be what you want." (007 female encamped IDP, Malkohi)

“... in my opinion, if I could get somewhere where I would not go through the horror I went through in the past then local integration or resettlement is what would work for me." (003 Male encamped IDP, Malkohi)

However, for some female IDPs, being married means it is not up to them to decide which option to accept. For instance, a female IDP indicated her willingness to oblige with her husband's choices and decisions even if they were against hers:

“...you see even if I choose resettlement, if my husband does not like it then there is nothing I can do but to follow him and return... but I personally prefer resettlement. But if everything normalises, no one will dislike their home... no place like home." (20 Female encamped IDP, Fufore)

This thinking shows that there is a gender dimension to decision-making during displacement and exile. 
Traditional androcentric norms which give men the power to decide what to do in the family appear to also influence how decisions are made within families even in emergency situations. Even though the principle of durable solution requires giving displaced persons the opportunity to make voluntary decisions on whether or not to return to their place of origin, there is a sense that some displaced women lack the decision-making power.

Although some male encamped displaced persons have cited safety and previous experience of violence as the main reason for rejecting voluntary repatriation, more women have echoed this concern during interviews. This is not surprising given that women and children were targets of abductions, rape and enslavement by the Boko Haram terrorists. Some of the participants narrated how they were forced to watch the gruesome execution of their sons and husbands by the terrorists.

\section{Loss of livelihoods}

Another important reason IDPs gave for their preference of local integration over voluntary repatriation is the loss of economic livelihood following the war and displacement. As one male participant stated during the interview:

"all that we had is lost now. Even before we left, everything we had was burnt or stolen. My farm, my house, my belongings... Now we do not have anything... even if we are to go back, where can we even start...?" (019 Male encamped IDP, Fufore)

These participants believe that it would not be possible to rebuild their livelihoods if they were to go back to their place of origin. They believe that it is easier to setthe in their place of displacement and rebuild their livelihoods than in the war-torn villages and towns they fled.

In addition to loss of livelihoods support systems following violence, persecution and exile, some IDPs also indicated that availability of immediate needs and safety are major reasons given for the choice of local integration.

\section{Vulnerability, powerlessness and uncertainty}

Vulnerability, powerlessness and uncertainty are also some of the concepts that emerged in the views expressed by participants who prefer local integration or resettlement. Vulnerability was echoed as a factor that may prevent them from return. The perception of powerlessness on the part of displaced persons as well as the feeling of uncertainty as to what the future may hold after return have also been echoed to justify the choice of local integration over return.

As can be seen from the quotations of participants above, displaced persons living in government run camps are more likely than self-settled IDPs to express desires for local integration or relocation and reject voluntary return to their area of origin.

Majority of self-settled IDPs interviewed reject the idea of local integration. For instance, two self-settled IDPs mentioned the following reasons during an FGD:

"As I told you earlier, we are well received by the Fulani community here. However, everyone of us is anxious to return home. They gave us land to farm, yet their cattle encroached on our farms all the time and we cannot confront them." (Male self-settled IDP, FGD)

"I swear to Allah, we have never received assistance from either Gwoza local government or the Borno state government. We are not receiving assistance as those in the nearby camp. And no matter how long we live here, the hosts will continue to treat us a Gwoza not Adamawa people. So... there is no point in remaining here once Gwoza is safe for return." (Male self-settled IDP, FGD)

\section{Voluntary repatriation}

Study participants who expressed preference for voluntary repatriation/return to their homes cited socioeconomic reasons such as reunion with their families and restoring of severed social and community networks as their major concern. Another concern salient in the narratives of participants who prefer voluntary repatriation is the need to rebuild livelihoods. Participants also mentioned 'attachment to home' as an important motivation for return. It is, however, important to note that all participants who consider return as their most preferred choice have identified peace and safety as a precondition for return.

"To be candid, if it was possible, return to Gwoza would be the best solution. If peace returns to Gwoza and every village is secure, you will not find a single individual here tomorrow. All of us will go back." (Self-settled male IDP, FGD)

\section{Reunion with family}

The need to reunite with family and relations has emerged as the most widely mentioned reason for return by all categories of IDPs who see voluntary repatriation as the most viable of the three traditional durable solutions to their displacement.

"...if home is safe, going back home would be the best, you have your remaining relatives, your kids would also know their relatives, you would be free, there is no place like home, that is if it is safe. But if 
it is not, anywhere, a Nigerian would stay." (004 self-settled male IDP)

"I would choose returning if I could get the necessary support I needed, such as capital to start my business. My mother is still alive and there are orphaned children of my late brother who was killed by the terrorists, 7 of them. I took them to Maiduguri and came back... and I have a female sister there, so I took them to her. They are going back to my village from Maiduguri... it was Allah's will that we are separated. I and my husband, with our two kids were here before. But, as people were going back to Maiduguri, they followed them... It is destined to be like that... I will return back to my village and work. At least I have stayed long enough in displacement. Almost two years, I praise Allah" (024 Female encamped IDP)

Apart from safety, the participants quoted above imply that a sustainable return home to reunite with family requires economic support through the provision of capital and skills. The first participant quoted further added that from the information they are receiving from those who fled recently, the area is still not secure, as raids by insurgents and armed confrontations with the military are still ongoing.

\section{Restoring social and community network}

A number of IDPs emphasised the importance of social and community ties which were severed following displacement and exile. Such participants opined that if they would be safe and protected, return would be a more desirable and sustainable solution, as it offers them another opportunity to restore and rebuild their social and community network. As can be seen from the view expressed by the participant quoted below, status deprivation during displacement is another reason advanced by a small number of participants who preferred repatriation over local integration and resettlement.

"if the war ends, and peace returns, it would be necessary for me to go back home, since I am a community leader... I have followers, but if there is no peace, I would rather remain here or resettle elsewhere in the region" (009 male encamped IDP)

Despite their cultural connections to 'home' and the need to restore social and community ties, this category of IDPs has serious concerns over security and safety.

\section{Rebuilding livelihoods}

Displacement and exile were viewed by many of the IDPs we interviewed as involving the loss of livelihood resources and other sources of life support. Accordingly, the need to recover lost natural capital, especially land, as well as job was found to be one of the major reasons for wanting to return home among mostly self-settled IDPs. Also, lack of access to natural and man-made capital in their place of refuge and the hope that some of the life-supporting resources that are missing would be regained upon return were mentioned by IDPs:

"...farming was our major occupation that sustained us in the past. We used to feed and clothe ourselves from what we got from our farms. Even our weddings and childbirth were funded from the proceeds of farming. There was nothing that we used to do to get sustenance other than farming. Before we came here, all of us were self-sufficient, we never knew anything called begging, neither did we depend on anybody to help us with anything. It was after we arrived here that we began to realise that a human can be so helpless and dependent on others. We never knew anything like this. We are historically an independent and hardworking people...So for us, if we can get back to our farmlands to use our labour and cultivate, we would be grateful to Allah." (Self-Settled IDP FGD)

As indicated by the participant quoted above, return home could guarantee self-sufficiency and sustainable income and, in effect, bring an end to their current state of 'dependency' and 'helplessness'. A durable solution to this category of IDPs is one that would guarantee sustainable income through self-reliance and independent pursuit of economic goals.

One major distinction between self-settled and encamped IDPs is access to land for farming. Self-settled IDPs in Malkohi village, for instance, have revealed that the host community has provided them with lands for both settlement and farming. IDPs living in governmentrun farms do not have land where they can farm. Despite having access to land and freedom of movement, majority of self-settled IDPs in Malkohi village prefer voluntary repatriation over local integration. These IDPs mentioned stigmatisation in the host community, tension between IDP farmers and their pastoral hosts and lack of humanitarian assistance to self-settled IDPs compared to those in camps as some of the reasons why they prefer voluntary return.

\section{Passivity, resignation and pessimism}

There were a few IDPs interviewed who indicated that they were willing to accept any solution offered to them. The variety of views this category of participants expressed during interviews and FGDs indicate passivity, resignation and pessimism. 
The first set of views is based on the belief in divine destiny, that is, the view that 'everything is controlled by God', including their sustenance and their future. This belief leads to 'submission' to the will of God as a means of coping with situations where individuals are faced with difficult choices that require difficult decisions. Although the belief has featured prominently throughout the data, some participants have used it to express their indifference and passivity regarding durable solutions:

"Well, the earth belongs to Allah... south, north, east and west...yeah... whichever place is more peaceful is the best... (okay) so... if I were asked to choose one... whether home or here or elsewhere..., to be candid, if we can have the house and other things, anywhere is okay" (016 male encamped IDP)

Even though this participant has surrendered his affairs to the will of God, he still underscores the need for sustainable housing and other life-supporting resources wherever he finds himself. Another participant suggested that whether she is asked to return, integrate or relocate, her major needs are food and farmland to feed her orphaned children and a house to live in:

"...well either going home or settling here or in a new place... all that is required is two things - food and land, as for health, it is in the hands of Allah... orphans' care is also in the hands of Allah... that is my thought" (019 female encamped IDP)

Some participants suggest that while they are willing to accept any solution presented to them by the government, they are pessimistic the government is sincere, committed and capable of fulfilling its promises. The participant quoted below was implying that institutional failures and lack of sincerity will prevent any effective implementation of durable solutions in a way that would address their livelihood needs:

"Well, there is one thing, the Nigerian government is good at making empty promises, whether you go home or stayed here it all depends... if you go home you may yet be homeless, if you stay here for how long would you stay?" (020 male encamped IDP)

In addition to the feeling that the government lacks the capacity to support them to meet their basic economic and social needs, there is an obvious fear of 'homelessness' after return and 'uncertainty' in the case of local integration among some IDPs. The tension resulting from these conflicting possible outcomes is resolved by fatalistic beliefs in divine preordination and destiny. This thinking on the part of IDPs underscores the pitfalls of institutional failures such as corruption and inefficiency on humanitarian assistance and development in conflict situations.

\section{Durable solutions, peace and security}

A major recurrent theme in the narratives of all participants regardless of preferences of durable solution is the issue of peace, security and an end to the war. Both IDPs who preferred voluntary repatriation identified insecurity and the continuation of fighting as the biggest obstacle to the realisation of their dream of returning home:

"The problem is Boko Haram is still in control of much of the area around Gwoza. The entire villages outside of the town of Gwoza is still under Boko Haram. They are everywhere. You cannot even go outside the town to get firewood with a military escort and even with the escort you must be very quick, otherwise they would attack you." (Male selfsettled IDP, FGD)

"The area is still unsafe. You see this man (points to one of the IDPs standing), he has been living in Gwoza. He just escaped from the town two weeks ago. He is now here looking for a place to live." (Male self-settled IDP, Malkohi village)

Another participant in the FGD added:

The military conducted a patrol once outside the town and sacked Boko Haram from two neighbouring villages. But since then, the did not make any attempt to expand their operations outside the town. They even rescued some villagers who were unable to escape, including one of my nieces who is crippled. She was brought to Gwoza by the army during that operation. They did that operation with the help of local vigilantes. They did another operation in Belneke once, that is all. But within the town of Gwoza, there is peace. But outside the town, there is no security at all. (Male self-settled IDP, FGD)

In addition to echoing the view that Boko Haram is still in control of much of the areas the Nigerian military claimed to have liberated in Borno, many IDPs pointed out that they do not expect the military to end the war and restore normalcy in the area anytime soon. We asked one the officers responsible for camp management about how they are implementing durable solutions when security remains a big challenge. He responded:

"We have done a durable solution survey here recently. The governor Adamawa State has formed a durable solution committee which comprises of all 
major humanitarian agencies operating in this state. Based on our survey, majority of them want to go back home, if their towns and villages are secure. A few of them said they prefer to be resettled elsewhere. And you know, they are different people with different preferences and experiences... The main challenge is the war is still going on. The military had reclaimed some territories previously governed by the terrorists. But the war is far from over... and we cannot allow them to return only to be displaced again, abducted, or even killed."

These views show that achieving durable solutions to the problem of protracted displacement in the Northeast Nigeria depends on the actual resolution of the conflict and an end of all armed hostilities. As one female IDP recalled, Boko Haram had followed them to their place of refuge in Malkohi camp, Adamawa, and carried out a suicide bomb attack that killed a scores of IDPs and camp officials in September 2015. According to her, even after resettlement or local integration, IDPs still have concerns over the ability of the government to prevent future displacement and keep them safe from Boko Haram's violence.

\section{Discussion and conclusion}

The 2030 Agenda for Sustainable Development which ushered in the Sustainable Development Goals in 2015 was anchored on the mantra of 'leaving no one behind'. A year later, the World Humanitarian Summit drew from the 2030 Sustainable Development Agenda and introduced the idea of 'working together differently to end (humanitarian) needs' (Blind 2019). The idea linking humanitarian action with development, although not new, has received renewed attention with the unveiling of the 2030 Sustainable Development Agenda. In humanitarian crisis situations, the concept of durable solutions offers an analytical lens for exploring the humanitarian and development needs of vulnerable populations and the social and institutional challenges of addressing those needs. However, what appears to be missing from decades of research on sustainable solutions to violenceinduced displacement is a critical understanding of the views and preferences of the IDPs.

The analysis presented above tries to gain the perspectives and preferences of both encamped and self-settled displaced persons on durable solutions to displacement due to the Boko Haram war. The central assumption of our analysis is that, despite their peculiar vulnerabilities, IDPs are social agents that have needs and choices and preferences. Thus, sustainable solutions to the problem of large-scale protracted displacement are those that consider and reflect the needs and choices of the people suffering from the consequences of violence and displacement. Our analysis therefore explores views and preferences of IDPs on the permanent solution to their displacement.

As the data shows, variations exist in IDPs' needs and preferences of durable solutions as well as the reasons given for the choice and desires of durable solutions. Despite the variations, it appears all the reasons given by IDPs to rationalise their preferred durable solution reflect the overall goals of development and sustainability. For instance, to IDPs who rejected voluntary return, local integration, safety and security, economic empowerment are the major considerations. For IDPs who see voluntary repatriation as the appropriate durable solution, major reasons include restoration of family and community network and rebuilding livelihoods, regaining economic independence and self-reliance. Another reason is emotional connection to the place of origin. Although the majority of IDPs were displaced from the same place (Borno and Adamawa State), desire for voluntary return is more common among self-settled IDPs than encamped IDPs. A common thinking among both IDPs who desire local integration and those who prefer return is the expectation of gaining economic opportunities after the implementation of a durable solution. The last category of IDPs showed indifference and fatalism towards durable solutions. Their perspectives seem to be influenced by either religious beliefs in preordination or lack of trust in government and humanitarian institutions. Finally, there was a sense of fear among many IDPs and some humanitarian officials that durable solutions can hardly be achieved in foreseeable future unless the government is ready and able to completely prevent Boko Haram from attacking civilians in the entire region. These findings suggest that in situations of largescale displacement such as the case of the Northeast Nigeria, IDPs think and hope for a future beyond ad hoc emergency humanitarian relief and assistance. Although displaced persons have diverse preferences and wishes, there is evidence that they seek solutions that would address their vulnerability, poverty, impoverishment and vulnerability. As their different voices suggest, whether they choose voluntary repatriation or local integration or relocation, IDPs expect not just permanent protection from violence but also sustainable employment, housing, education and healthcare among other essential development services and opportunities. These solutions can only be provided if humanitarian efforts are integrated into the overarching development agenda and programmes of governments.

As the poorest and most vulnerable members of the society, displaced victims of violent conflicts deserve a special development intervention that will be specifically targeted at improving their economic self-reliance, while reducing the risks of vulnerability, homelessness and 
powerlessness. If anything, the voices of IDPs in this study suggest the need to reconsider the current thinking on traditional durable solutions where states and international organisations practically recognise voluntary repatriation as the 'best' and 'ideal' solution (Long 2010,2014 ) to conflict-induced displacement.

Finally, the Nigerian government and development actors need to come up with a holistic approach to support these poorest and most vulnerable members of the society to overcome the risks of impoverishment caused by war and displacement. In other words, there is an urgent need for a special development intervention specifically targeted at improving their economic self-reliance by providing them with the necessary assets, skills and other resources needed to build sustainable livelihoods. Such an approach needs to engage and include the IDPs and other victims of the war in the development and planning of the interventions.

\section{Acknowledgements}

The authors wish to acknowledge the contribution of Bashir Malam during the collection of data.

\section{Authors' contributions}

MS developed the study design and methodology. MS and AA conducted separate interviews with the study participants and moderated the focus group discussions. AA transcribed the audio records of interviews. AA also conducted the literature search and review. MS and AA jointly performed the analysis and interpretation of data. MS wrote the initial manuscript. AA made provided a useful contribution in rewriting the initial manuscripts. The authors read and approved the final manuscript.

\section{Funding}

Funding for this study was provided by the Tertiary Education Trust Fund of Nigeria through the Gombe State University. The funding body and the beneficiary university did not play any role in the design of the study, collection, analysis and interpretation of data and in writing the manuscript.

\section{Availability of data and materials}

The datasets generated and analysed during the current study are not publicly available. This is because the ethical guidelines for the study, as approved by the Gombe State University Research Committee, provides that interviews and focus group discussions transcripts shall be stored securely, and access can only be given to those directly responsible for analysing the data.

\section{Competing interests}

The authors hereby declare that they have no competing interests in the current study.

Received: 21 October 2019 Accepted: 30 November 2020

Published online: 08 December 2020

\section{References}

BBC World Trust (2010) Nigeria talks climate change: the public understanding of climate change. BBC World Service Trust, London

Blind PK (2019) Humanitarian SDGs: Interlinking the 2030 Agenda for Sustainable Development with the Agenda for Humanity. United Nations Department of Economic and Social Affairs, New York

CGDEV (Center for Global Development) (2017) Bridging the humanitariandevelopment divide: three priorities from three global leaders. Available at: https://www.cgdev.org/blog/\%0Abridging-humanitarian-development-dividethree-priorities-three-global-leaders.

Cohen R (2008) Listening to the voices of the displaced: lessons learned. Brookings Institution, Washington, DC
Eriksen SH, O'Brien K (2007) Vulnerability, poverty and the need for sustainable adaptation measures. Climate Policy 7:338-352

Federal Ministry of Environment (2014). United Nations Climate Change Nigeria. National Communication (NC). NC 2. 2014. Available at: https://unfccc.int/ sites/default/files/resource/nganc2.pdf.

Fielden A (2008) Local integration: an under-reported solution to protracted refugee situations. UNHCR, Geneva, p 158

Inter-Agency Standing Committee (2010) IASC Framework on Durable Solutions for Internally Displaced Persons. The Brookings Institution-University of Bern Project on Internal Displacement Available at: https:// interagencystandingcommittee.org/system/files/iasc_framework_on_ durable_solutions_for_idps_april_2010.pdf

IOM (2015) An assessment of psychosocial needs and resources in Yola IDP Camps arising from conflict-induced displacement in North East Nigeria. Yola.

Long K (2010) Home alone? A review of the relationship between repatriation, mobility and durable solutions for refugees. UNHCR, Geneva, p 4

Long K (2014) Rethinking durable solutions. In: Qasmiyeh F-E et al (eds) The Oxford Handbook of Refugee and Forced Migration Studies. Oxford University Press, Oxford, pp 476-488

National Bureau of Statistics (2019) Poverty and Inequality in Nigeria, Abuja Available at: https://nigerianstat.gov.ng/elibrary?queries[search]=poverty

OCHA (2018) North-East Nigeria: Humanitarian Situation Update, Maiduguri Available at: https://reliefweb.int/report/nigeria/north-east-nigeriahumanitarian-situation-update-progress-key-activities-2018-1

Punch News (2018) 1,500 schools destroyed by Boko Haram in North-East - FG, 4 May. doi: https://punchng.com/1500-schools-destroyed-by-bharam-in-northeast-fg/.

Schafer J (2002) Supporting livelihoods in situations of chronic conflict and political instability : overview of conceptual issues Overseas Development Institute London. The Livelihoods and Chronic Conflict Working Paper Series. Available at: The Livelihoods and Chronic Conflict Working Paper Series, London, p 183

Schipper L, Pelling M (2006) Disaster risk, climate change and international development: scope for, and challenges to, integration. Disasters 30(1):19-38

Strömberg D (2007) Natural disasters, economic development, and humanitarian aid. Journal of Economic Perspectives 21(3):199-222. https://doi.org/10.1257/ jep.21.3.199

Tamminga P (2011) Sustainability in humanitarian action. In: International Conference of the Red Cross And Red Crescent: Sustainable Humanitarian Action: Bridging relief to development, Geneva, pp 1-6 Available at: http:// daraint.org/wp-content/uploads/2011/12/Sustainability-in-humanitarianaction.pdf

UNDP (2018) Responding to the Lake Chad Basin crisis, Crisis Response. Available at: http://www.undp.org/content/undp/en/home/crisis-response/on-goingcrises/northeast-nigeria.html (Accessed: 29 Oct 2018).

UNDP (2020) Early Recovery Programme for the North East, Abuja Available at: https://www.ng.undp.org/content/nigeria/en/home/operations/projects/ environment_and_energy/Early_Recovery_Programme_for_the_North_East. html

UNFCCC (2007) Climate change: impacts, vulnerabilities and adaptation in developing countries. UNFCCC, Bonn

\section{Publisher's Note}

Springer Nature remains neutral with regard to jurisdictional claims in published maps and institutional affiliations. 